\title{
Identifying water sources and reassessing aquifer boundaries in West Hawai'i, USA
}

\author{
DiAMOND K. TACHERA ${ }^{1 *}$, NiCOLE C. LAUTZE ${ }^{2,3}$, \\ HENRIETTA DUlai ${ }^{1}$, CHRISTOPHER K. SHULER ${ }^{3}$, \\ DONALD M. THOMAS ${ }^{2}$
}

${ }^{1}$ Dept. of Earth Science, University of Hawai'i at Mānoa, Honolulu, HI 96822, USA (*correspondence: diamondt@hawaii.edu)

${ }^{2}$ Hawai'i Inst. of Geophysics and Planetology, University of Hawai'i at Mānoa, Honolulu, HI 96822, USA

${ }^{3}$ Water Resources Research Center, University of Hawai'i at Mānoa, Honolulu, HI 96822, USA

Groundwater is the primary source of fresh water in Hawai'i. Such a valuable resource, however, may be negatively affected by over-pumping and contamination, but its movement in the subsurface is not well understood. Currently, hydrologic units for groundwater management are delineated by the State of Hawai'i Department of Land and Natural Resources Commission on Water Resource Management, and their boundaries are primarily based on surface features and limited subsurface geologic information. Recent ground-truth information from coredrilling suggests that subsurface geologic conditions are more complex than current hydrological models account for, and exert a large influence over groundwater storage and flow. As such, there are large uncertainties in groundwater flow paths, including from areas of recharge to their ultimate discharge. A data driven method for better understanding these subsurface properties is needed.

This presentation will discuss groundwater geochemistry results from the Hualālai aquifer, located in the western side of Hawai'i Island, focusing on three main findings: first, we reassess aquifer boundaries based on new water stable isotope results that provide possible flow paths based on determined recharge elevations; second, we investigate the thermal influence of Hualālai's rift zone on dissolved ion and metal concentrations, thus affecting the quality of groundwater and providing unique chemical characteristics that extend kilometers beyond the rift zone; and third, we explore geochemical differences between high-level and basal groundwaters to better understand the connectivity between these aquifers. 